\title{
Igualdad de género y animación infantil en España: Myriam Ballesteros
}

Gender equality and children's animation in Spain: Myriam Ballesteros

- Natalia Martínez y Nerea Cuenca

Universidad Carlos III y Universidad Rey Juan Carlos, España

Fecha de recepción: 15 de abril de 2020

Fecha de aprobación: 2 de junio de 2020

DOI: http://dx.doi.org/10.15304/ricd.3.12.6754

\section{NOTAS BIOGRÁFICAS}

Natalia Martínez es profesora ayudante doctora en el departamento de Comunicación en la Universidad Carlos III de Madrid y miembro del grupo de investigación Televisión-Cine: memoria, representación e industria (TECMERIN). Sus últimas publicaciones se encuentran en los volúmenes Guerras simbólicas. El papel del audiovisual en la lucha contra la violencia de género (UIB, 2017) e Imaginarios digitales del Sur: historias de pertenencia y desarraigo en los cines hispánicos (Peter Lang, 2019).

Contacto: nmperez@hum.uc3m.es

Nerea Cuenca es doctora en Ciencias de la Comunicación y Humanidades por la Universidad de Burgos con la tesis doctoral La construcción del género en las películas de Pixar Animation Studios entre 1995 y 2015: Modelos de masculinidad, feminidad y relaciones entre personajes. Desde 2009 trabaja en la Universidad Rey Juan Carlos. Miembro del Grupo de Investigación Visual.

Contacto: nerea.cuenca@urjc.es

\section{Resumen}

Los medios de comunicación transmiten valores, normas de comportamiento y modelos de actuación que se convierten en referentes para la sociedad, especialmente para la infancia, cuando su discurso es aceptado. Por ello es importante reparar en el tratamiento que los contenidos infantiles otorgan a cuestiones como el género. Las series de animación infantil realizadas en España comienzan a emitirse en la televisión nacional a partir de los años ochenta y, en cuarenta años se han consolidado como un soporte para la producción de dibujo animado que incluso vende a otros países. Al mismo tiempo, la presencia de mujeres en todos los departamentos involucrados en la producción de películas, cortos y series de animación ha crecido también, una circunstancia muy alejada a la de hace cinco décadas, cuando su trabajo se reducía a "hacer el color". A partir de la trayectoria de la directora y showrunner Myriam Ballesteros, el presente texto examina la situación de las mujeres creadoras en la animación española y ofrece un análisis de los valores que vehicula una de sus series de mayor éxito: Lola y Virginia (Disney Channel: 2006-2009).

\section{Abstract}

Mass media embody values and performance standards that become role models. Society, especially children, has internalized media discourse. It is necessary to analyze gender discourses within children's television programs. Children's entertainment arose in Spanish television during the 
eighties and has established itself as one of the most important European industries. At the same time, the presence of women in animation departments has widespread. A very different situation from five decades ago, when women's work was just "coloring". This paper examines the career of the Spanish showrunner Myriam Ballesteros and women directors in Spanish animation. We also analyze one of Ballesteros's most successful TV shows: Lola and Virginia (Disney Channel: 20062009).

\section{Palabras clave}

Animación infantil, historia de la televisión en España, autoría femenina, igualdad de género, Myriam Ballesteros.

\section{Keywords}

Children's animated televisión, history of televisión in Spain, female authorship, gender equality, Myriam Ballesteros.

\section{Sumario}

1. Introducción

2. Las series de animación en España

3. Mujeres en la industria de la animación española

4. Myriam Ballesteros, productora y creadora de animación

5. Marco teórico y metodología

6. Lola y Virginia: una lectura con perspectiva de género

7. Conclusiones

\section{Summary}

1. Introduction

2. The animation series in Spain

3. Women in the Spanish animation industry

4. Myriam Ballesteros, producer and animation creator

5. Theoretical framework and methodology

6. Lola and Virginia: a reading with a gender perspective

7. Conclusions 


\section{INTRODUCCIÓN}

En 2015, la Organización de las Naciones Unidas (ONU) aprobó la Agenda 2030 sobre el desarrollo sostenible, una oportunidad para que los países y sus sociedades emprendiesen nuevos caminos para mejorar la vida de la ciudadanía. El gobierno de España junto a otros 180 países se comprometió con esta agenda, que cuenta con 17 Objetivos de Desarrollo Sostenible (ODS), que implican desde la eliminación de la pobreza hasta el combate al cambio climático. Entre ellos también se incluye el compromiso de la comunidad internacional para lograr la iguaIdad de género y el empoderamiento de todas las mujeres y niñas.

Los medios de comunicación no son ajenos a estos objetivos y, tanto las cadenas privadas de televisión como el ente público Radio Televisión Española (RTVE), han puesto en marcha campañas con el objetivo en darles visibilidad. Por ejemplo, el pasado 8 de marzo, con motivo del Día Internacional de la Mujer, RTVE se sumó a la lucha por la igualdad con una campaña bajo el lema La fuerza eres tú, y que, como indica su web, "este año enmarcado en su campaña por los Objetivos de Desarrollo Sostenible (ODS 5: igualdad), RTVE está comprometida con la defensa de la igualdad de trato y oportunidades entre mujeres y hombres" 1 . Los medios, por tanto, son conscientes de que poseen un poder de representación fundamental a la hora de construir y deconstruir los roles y relaciones de género que, por supuesto, afectan a la socialización. Esto se articula especialmente durante la infancia y la juventud, periodos fundamentales para la comprensión de la realidad social.

Los contenidos televisivos importan tanto porque, a partir de sus historias e imágenes, se crean significados en torno a la masculinidad y la feminidad. Los programas y ficciones emitidas por televisión influyen en la adquisición de esas pautas sociales y culturales. Para comprender la relevancia que ejercen los programas de televisión sobre la infancia, resulta necesario señalar que los seres humanos somos totalmente susceptibles a la adaptación del entorno durante los primeros años. "Los modelos y expectativas sociales básicos, entre los que figuran el sexismo o la igualdad, una vez aprendidos son difíciles de modificar actuando como una segunda piel" (Bengoechea et al., 2005, p. 7). De esta forma, el poder de representación que tienen los medios de comunicación, especialmente la progra- mación infantil, afecta a la forma en que las niñas y niños perciben su entorno y realidad social.

En los últimos años, las cadenas de televisión, tanto públicas como privadas, se han involucrado en nuestro país de una manera muy activa en la consecución de la igualdad entre hombres y mujeres, incorporando temas a su agenda informativa como la violencia de género, la brecha salarial, la discriminación laboral... Con sus dificultades, este compromiso también se advierte en la creación de contenidos de entretenimiento y de ficción, así como un mayor cuidado por los contenidos elaborados para el público infantil. Es por ello que las series de animación infantil españolas han utilizado formatos innovadores para ejercer eficazmente el papel de educar y entretener a los más jóvenes, no sólo a nivel nacional sino también en gran parte del mundo. "Muchas productoras españolas se han sumergido en la creación de contenidos audiovisuales de animación infantil y, por otro lado, ha sido, históricamente, la televisión pública la responsable de emitir gran parte de los dibujos animados realizados en España" (Jiménez Sánchez, Lavín y Gómez Isla, 2019, p. 37).

Las series de animación infantil realizadas en España comienzan a emitirse en la televisión nacional a partir de los años ochenta, compitiendo sobre todo con las producidas en Japón y Estados Unidos. Cuarenta años después, las series españolas se han consolidado como un soporte para la producción de dibujo animado que incluso vende a otros países. Al mismo tiempo, la presencia de mujeres en todos los departamentos involucrados en la producción de películas, cortos y series de animación ha crecido también, una circunstancia muy alejada a la de hace cinco décadas, cuando su trabajo se reducía a "hacer el color". Si bien ahora encontramos mujeres en los estudios de animación, los rodajes y en las escuelas que imparten esta técnica, el porcentaje de mujeres en los puestos artísticos sigue siendo minoritario, tal como sucede en el resto de la industria audiovisual. A partir de la trayectoria de la directora y showrunner Myriam Ballesteros, el presente texto examina la sitúación de las mujeres creadoras en la animación española y ofrece un análisis de los valores que encontramos en una de sus series de mayor éxito: Lola y Virginia (Disney Channel, 20062009).

\section{LAS SERIES DE ANIMACIÓN EN ESPAÑA}

Los orígenes de la animación española los encontramos a principios de siglo XX de las 
manos de Segundo de Chomón con sus producciones de carácter experimental: El teatro del pequeño Bob (1908) y El hotel eléctrico (1908). "En 1932, se funda la Sociedad Española de Dibujos Animados (SEDA). Cuatro películas acábadas y varias sin terminar constituyen todo el legado que dejaron hasta que estalló la guerra civil" (Jiménez Sánchez, Lavín y Gómez Isla, 2019, p. 38). La década de los cuarenta dejó como legado cuatro largometrajes de animación, como Garbancito de la Mancha (Arturo Moreno y José María Blay, 1945). A pesar de que relataba las penurias de la España de la época, fue todo un éxito y se declaró de interés nacional por el régimen. "El primer largometraje de animación venía de la mano de Arturo Moreno y en Dufaycolor con lo que también se catalogó como la primera película de animación europea en color" (Yébenes Cortés, 2016, p. 9). Sin embargo, no es hasta los años sesenta cuando la animación comienza una edad de oro de manos de la publicidad que, primero en los cines, y luego en la Radio y Televisión Española (RTVE), consigue que los estudios obtengan beneficios económicos para realizar cine de animación. "Fue una etapa de gran producción, con centenares de películas, premios internacionales, y dominada por un estilo Disneyano que marcó escuela en los Estudios Moro. Muestra de ello es el spot Vamos a la cama (1965)" (Jiménez Sánchez, Lavín y Gómez Isla, 2019, p. 38).

En Estados Unidos la animación era una carrera universitaria que se podía estudiar, por ejemplo en CalArts (1961), la academia de artes donde los directores y creativos de animación de los estudios Disney ejercían como profesores de nuevos estudiantes que se abrieron paso en los 80 y 90, como John Lasseter ${ }^{2}$ o Tim Burton ${ }^{3}$ (Paik, 2007: 30). En nuestro país, y muy especialmente en Cataluña, es durante la década de los 70 cuando comienzan a trabajar los primeros animadores, un grupo de creativos que desempeñaba esta actividad como afición (Manzanera, 1992).

Los animadores españoles eran autodidactas o salían del país para aprender el oficio. Muchos de ellos, volvían a España y aquí montaban sus estudios como autónomos donde trabajaban en los encargos que recibían del extranjero. Un buen ejemplo de esta dinámica de trabajo son los estudios Filman, que participaron en Los Picapiedra (ABC: 1960-1966), o Lápiz Azul Animación S.A., que trabajaron en diversos proyectos para la Walt Disney y la Warner Bross (Jiménez Sánchez, Lavín y Gómez Isla, 2019: 38-39). Entre los animadores de este periodo, cabe destacar la figura de Cruz Delgado, quien, en esos años pone en marcha una serie que tuvo gran éxito entre el público infantil Don Quijote de la Mancha (1978) (Jiménez Sánchez, Lavín y Gómez Isla, 2019: 38).

Con el éxito de Delgado, comienza el auge de la emisión de series de animación producidas en nuestro país (Jiménez Sánchez, Lavín y Gómez Isla, 2019: 37). Este florecimiento de la animación llevó a España al primer puesto en cuanto a producción de minutos de animación y este reconocimiento nos convirtió en productores para el extranjero, naciendo así la industria de la animación española que se basa en las series de televisión y presta servicio al extranjero (Martínez, 2009). Algunas de las series de esta época fueron Ruy, el pequeño Cid (TVE: 1980), Mofli, el último koala (TVE: 1987), Las mil y una Américas (TVE: 1989-1991), Los Fruitis (TVE: 1990-1991) y Cuttlas (Canal +: 1992-1994).

El éxito de las series de animación españolas es tal que se prolonga también en los 90 (Jiménez Sánchez, Lavín y Gómez Isla, 2019: 37). Esta conquista del mercado debe mucho a la nueva legislación en España de 1986 con la que comienza la reducción de la producción de cine y de cortometrajes. Hasta entonces, era habitual estrenar un corto de animación antes de comenzar la proyección del largometraje en las salas de cine. En la nueva legislación se determinó que ya no era obligatorio insertar un cortometraje $y$, por tanto, las productoras buscaron ingresos en la publicidad y en la televisión para no perder ingresos (Martínez, 2009). Con este nuevo panorama legislativo, la Comunidad Económica Europea estableció medidas para promover y fomentar la producción de series de animación. Y, a pesar de que el objetivo era ambicioso, se llevó a cabo de manera lenta y resultó efectivo (Jiménez Sánchez, Lavín y Gómez Isla, 2019: 39).

El éxito de las series de animación españolas continuó en los 90, pero adaptándose a los nuevos tiempos. Los nuevos canales de televisión en abierto (Antena 3, Telecinco y Canal +), no solamente sirvieron de escaparate, sino que también invirtieron en las series de animación nacionales (Jiménez Sánchez, Lavín y Gómez Isla, 2019: 29). El alquiler de cintas VHS y la venta de largometrajes en este formato impulsó aún más la producción de la animación española (Jiménez, 2015). La nueva legislación exigió un ritmo frenético lo que supuso una reducción en la calidad del contenido y la estética de las series realizadas por las productoras españolas (Jiménez Sánchez, Lavín y Gómez Isla, 2019: 37). No obstante, década dio luz a grandes éxitos infantiles como 
La Banda de Mozart (TVE: 1995) o Las tres mellizas (TV3: 1997-2003).

Esta situación desembocó en una reducción de la producción española de series de animación a principios del nuevo milenio y las productoras de nuestro país se dedicaron a "buscar otros nichos de mercado" (Jiménez Sánchez, Lavín y Gómez Isla, 2019, p. 37). A principios del nuevo milenio surgieron éxitos nacionales e internacionales como Capelito, el bolet màgic (TVE3: 1999), Cálico Electrónico (2004-2015), Pocoyó (La2: 2005-2011), Los mundos de Alex (2007) o Sandra detective de cuentos (TVE: 2009-2010). En la última década, Suckers (Disney XD: 2010) o Invizimals: Únete a la caza (Clan: 2014) se han abierto camino en el mercado audiovisual de la animación. En unos años en los que la TDT (Clan TV, Neox o Boing), canales de pago (productoras como Disney o Cartoon Network respaldan estos medios) y plataformas virtuales (canales como YouTube Kids) se han convertido en los medios para lanzar las series de animación españolas dentro y fuera de nuestras fronteras (Jiménez Sánchez, Lavín y Gómez Isla, 2019: 37). Productoras como BRB, Neptuno, D'Ocon, Motion, Cromosoma, Myriam Ballesteros, Imira, Zinkia, Juan Ramón Pina o Anima2 -algunas aún en activo- fueron esenciales en el desarrollo de series de animación españolas.

\section{MUJERES EN LA INDUSTRIA DE LA ANIMACIÓN ESPAÑOLA}

Como en el resto de la industria audiovisual, el espacio de las mujeres en la historia de la animación en España ha sido reducido. Habría que esperar a las últimas décadas del siglo XX para encontrar nombres propios de mujeres creadoras y dibujantes, esto es, mujeres que lograran desarrollar una carrera con continuidad. A pesar de ello, en los años treinta encontramos en las rudimentarias productoras de animación equipos de mujeres jóvenes que trabajaban como coloristas para los celuloides, hecho que también acontecía en los equipos de producción de cómics, como en Hergé. Así, los equipos de animación española que contaban con chicas coloristas eran SEDA (Sociedad Española de Dibujos Animados), con producciones de carácter nacionalista a principios de los treinta, y el formado por Carlos Tauler en Madrid en 1941. En los años cuarenta, la industria de la animación comienza a afianzarse apareciendo estudios que cuentan con mujeres entre sus filas de dibujantes, como la compañía Dibujos Animados Chamartín. En ella estaba Enriqueta Calsina, en el equipo dirigido por Francisco Tur y centrado en la realización de Las aventuras de Don Cleque (1942-1944), y a Matilde Galindo, en el equipo dirigido por José Escobar y dedicado a la serie de aventuras animadas protagonizadas por el Toro Civilon (González Hijano, 2004). También el arriba citado Garbancito de la Mancha (1945) contaba con Rosa Galcerán, que ya había colaborado anteriormente en otro proyecto de animación, El capitán tormentoso, y con un "equipo de chicas coloristas, un total de veinte, del que estaba al frente Ana Melero" (González Hijano, 2004, p. 41). En esa época también se incorporaron a la industria Irene Dalmau, Conchita González y Pepita Pardell. Lucía González Hijano señala que "no será hasta ya entrados los sesenta que resurjan el nombre de las dibujantes, acalladas por el anonimato de las producciones publicitarias en estudios de animación como Estudios Moro o Estela Films" (2004, p. 42). Es en estos donde trabajaban los lápices de Nieves Gorriz, Isabel Belío, Irene Castellanos y Carmen Moliné, así como Ana María Gardoqui, una de las pocas profesionales de la animación de la productora Story Film.

Del mismo modo que sucede en la industria cinematográfica española, es en la década de los noventa cuando se produce la irrupción definitiva de las mujeres en el mundo de la animación, especialmente en la animación independiente. Además de Myriam Ballesteros, otras cineastas de ese momento son Ana Miquel, Alicia Carrianzo, Virginia Curia, Inma Rodríguez o Isabel Herguera. Esta última, afincada en Estados Unidos, ha desarrollado gran parte de su trabajo en formato videográfico utilizando toda clase de técnicas de animación como los recortables, pintura, arena, tizas... destacando Spain Loves You (1988), Safari (1989), El sueño de Iñigo (1990), Los muertitos (1993) y La gallina ciega (2005), nominada a los premios Goya en 2006. Por su parte, Mercedes Gaspar y Begoña Vicario afianzan sus respectivas carreras obteniendo numerosos galardones. Gaspar, tras dirigir varios cortometrajes como Sabía que vendrías (1992) o Su primer amor (1993), recibió el Goya al mejor cortometraje de animación con El sueño de Adán (1994), donde mezclaba diversas técnicas como pixilación y animación de objetos y fotografías. Begoña Vicario obtuvo también el Goya al mejor cortometraje de animación por Pregunta por mí (1996), que trataba la vida de una mujer migrante acechada por traficantes de órganos.

También en los noventa encontramos a Maite Ruiz de Austri, la realizadora con mayor producción de largometrajes animados. De hecho, 
ella misma indica: "Creo que soy la única mujer que ha dirigido y dirige películas de animación en España" (López Monjas, 2016, p. 16). Sus dos primeras películas, La leyenda del viento del Norte (1992) y El regreso del viento del Norte (1994), fueron producciones en colaboración con ETB y Euskal Media. La primera, dirigida junto a Carlos Varela y basada en leyendas vascas, fue posteriormente convertida en una serie de televisión de trece capítulos para ETB. Con uno de los presupuestos más elevados de la época, se estrenó el Día de la Energía en la Exposición Universal de Sevilla y consiguió la Medalla de Oro del Festival de Houston en 1992. En la segunda, Ruiz de Austri se situó en solitario al frente del guion y la dirección, llevándose el Goya a la mejor película de animación y la Medalla de Oro en el Festival de Houston en 1995 (González Hijano, 2004: 43-44). A estos títulos le siguieron, entre otros, iQué vecinos tan animales! (1998), La leyenda del unicornio (2001) y El tesoro del rey Midas (2010). Su último trabajo ha sido la adaptación como serie de animación de la popular trilogía literaria de Laura Gallego Memorias de Idhún (Netflix, 2019-).

A partir de la década de los 2000, destaca el trabajo de la productora gallega Chelo Loureiro, fundadora de Abano Produccións, y de Nathalie Martínez, propietaria de Blue Dream Studios Spain, un estudio de animación 3D, y cofundadora en 2017 de Wise Blue Studios, con sede en España y en Estados Unidos. También irrumpen nuevas cineastas como la valenciana Rocío Álvarez, cuyo cortometraje Simbiosis Carnal (2017) ha sido reconocido con diversos premios a nivel internacional. En la actualidad, la presencia de mujeres en todos los departamentos involucrados en la producción de películas de animación -color, iluminación, modelado, compositing...- es muy diferente a la de hace seis décadas. No obstante, quedan terrenos por conquistar. "En la animación independiente, tanto en largos como en cortos, hay mujeres que ocupan puestos de responsabilidad, pero se cuentan con los dedos de una mano las que dan el salto a la animación comercial" (López Monjas, 2016, p. 16). Y aunque las mujeres están presentes en los estudios de animación, en los rodajes y en las escuelas que imparten esta técnica, el porcentaje en los puestos artísticos sigue siendo minoritario, más aún en las posiciones técnicas.

\section{MYRIAM BALLESTEROS, PRODUCTORA Y CREADORA DE ANIMACIÓN}

Entre todas las mujeres creadoras de animación en España, Myriam Ballesteros (Jaén, 1960) ocupa una posición preeminente en su doble faceta de directora y productora de sus propios proyectos. Aunque nació en Jaén, desde los dos años ha residido en Vitoria (Ballesteros, 2020). En 1984 se licencia en Ciencias de la Información por la Universidad del País Vasco y, más tarde, estudia dirección y producción cinematográfica en la Universidad de Columbia en Nueva York (1987). Durante varios años realiza diversos cursos a nivel nacional e internacional: programación en la Agencia EFE Madrid (1985-1986), vídeo en la Escuela de Cine de Bilbao (1986), montaje en Creav \& Crepac en Francia (1986), realización y montaje en CEV Madrid (19851987), escritura cinematográfica en el Flemish European Media Institute (1988), producción televisiva en la BBC (1989), guion en la Universidad de Navarra (1990), dirección de actores en Piamonte Madrid (1991) y producción de dibujos animados y marketing cinematográfico en Media Programme (1992-1998). Estudiante inagotable, en los últimos años ha continuado formándose con postgrados en Gamificación en ICEMD-ESIC y en Transmedia y Social TV en la Universidad Rey Juan Carlos (Ballesteros, 2020).

La andadura profesional de Ballesteros comienza hace más de treinta años. Primero como ayudante de realización en magazines, deportes y vídeos institucionales en Videonor, y más tarde, como realizadora en EITB en informativos, el programa semanal sobre ciencia Evolución y un programa infantil, A la chita callando (19871990). También trabaja en otras cadenas, en Take TV como directora de concursos, programas de cocina, series de ficción, infantiles, y documentales (1990-1992), en Telemadrid como realizadora de una serie documental sobre arquitectura titulada Un Siglo de Madrid (1992). Ese mismo año funda MB Producciones y estrena su primer corto de animación, La Súperrabieta $(1993)^{4}$, que obtiene la Mención de honor y el premio a Mejor guion en el Festival Internacional de Cine de Alcalá de Henares Alcine. Posteriormente, dirige La leyenda del hombre malo (1994), un cortometraje coproducido con Euskal Media e inspirado el cuento vasco de "Patxi, el herrero" con Karra Elejalde, Álex Angulo y Mariví 
Bilbao entre sus protagonistas; la serie El libro de la luz y las tinieblas (1998) y La dama de Amboto (1999). Después de su experiencia en el cine de acción real, comienza a trabajar de forma continuada en la animación, dirigiendo y produciendo Memé y el Sr. Bobo (TVE: 1999), Memé y la pandilla (TVE: 2002) y Seis intrépidos (TVE: 2003).

En 2003, Ballesteros funda Imira Entertaintment, donde trabaja hasta 2015 como creadora y directora creativa de animación 2D y 3D. Tras varios proyectos pilotos, como Rip XL (2003), Hop \& Calamity (2004) y Ubloa (2005), pone en marcha las series Lola y Virginia (Disney Channel: 2006-2009), galardonada como Mejor Serie de animación en Cartoon on the Bay 2006; Sandra, detective de cuentos (TVE/Clan: 2009-2010), Mejor serie de animación en Zapping 2010 y Mejor serie de animación Nueva Mirada Festival 2011; Lucky Fred (Disney Channel: 2011-2014), Mejor serie de animación en Chicago International Children's Film Festival 2011 y Mejor serie de animación en Euro Film Festival 2011; Tube \& Victor (2013) y Mondo Yan (2014). En 2016, retoma MB Producciones, donde continúa en la actualidad trabajando en series como Annie \& Carola y Cenicienta enmascarada ${ }^{5}$. Myriam Ballesteros es socia de CIMA (Asociación de Mujeres Cineastas y de Medios) y socia fundadora de MIA (Mujeres en la Industria de la Animación). En 2019, junto a Alicia Núñez Puerto (directora de desarrollo creativo en Ánima Estudios), Nathalie Martínez (Wise Blue Studios), Belli Ramírez y Deneb Sabater (The Spa Studios), impulsa MIA. La asociación, tal como reza su página web, busca "romper el 'techo de cristal' en una industria donde el $35 \%$ de los empleados son mujeres según el Libro Blanco de la Animación"6. MIA cuenta con 700 mujeres y tiene entre sus objetivos dar voz y mejorar las condiciones de las mujeres en este sector, eliminar trabas y visibilizar la escasa representación y reconocimiento de su talento. Como indican en su manifiesto, "MIA se asienta sobre los valores de la equidad, la responsabilidad y la libertad".

\section{MARCO TEÓRICO Y METODOLOGÍA}

En los últimos treinta años, las historias contadas en la animación se han centrado en generar interés por las crisis internas, el arco de transformación que sufren los personajes y cómo los superan. Los deseos y las necesidades que van surgiendo, la toma de decisiones y aprender a afrontar cualquier situación frente a la resolu- ción de los conflictos han sido los que, principalmente, generan una evolución en los personajes animados (Finch, 2011). Esto ha repercutido en el diseño de las personalidades, que los aleja de los estereotipos literarios clásicos (Martínez González, 2011). Los que no han variado hasta el momento han sido los arquetipos narrativos y las funciones que desempeñan en la narración, postuladas por Vladimir Propp (Morfología del cuento, 1928) y Christopher Vogler (El viaje del escritor, 2002). En Morfología del cuento, Propp concretó que en todas las historias se repetían siete arquetipos o personajes modelo que contaban con unas funciones dramáticas determinadas repetidas una y otra vez en la tradición narrativa. Los siete arquetipos de Propp se clasificaban como buenos o malos (parámetros morales) en villano, héroe, auxiliar, donante, falso héroe, mandatario y la princesa y el rey (estos dos últimos en las obras literarias y los cuentos de hadas como una única unidad). A pesar de que hay muchas historias, Hollywood eligió el modelo descrito por Propp como referencia para crear sus guiones.

Por su parte, Christopher Vogler (2002) defiende la existencia de una serie de arquetipos que aparecen en las historias de aventuras: un héroe, una sombra, un heraldo, un mentor, un tramposo, un guardián del umbral y una figura cambiante. A partir de estos arquetipos narrativos se diseñan los personajes de cualquier narración audiovisual (Estévez, 2015: 409). El concepto "arquetipo narrativo" hace referencia a personajes comunes, sus símbolos y las relaciones que establecen siguiendo la denominación de arquetipo que Carl Jung propuso para los distintos modelos de personalidad humana (Vogler, 2002). Vogler resalta en su obra que cualquier personaje, independientemente de su raza, género o clase social puede representar alguno de estos arquetipos e incluso varios en una misma historia (2002). Asimismo, en las dos últimas décadas, cada vez son más numerosos los personajes femeninos que representan los arquetipos de heroína y villana, teniendo un gran peso narrativo tanto los personajes como sus funciones (Domínguez Morante, 2015: 50). EI análisis de la serie Lola y Virginia que proponemos a continuación está basado en los arquetipos narrativos de Propp y Vogler a partir de las fichas de análisis, elaboradas con la metodología de Cuenca Orellana (2019) ${ }^{7}$. El corpus de análisis lo conforman el primer y el último episodio de cada temporada, pues consideramos que son los más representativos. La elección como estudio de caso Lola y Virginia se debe a que, además de consolidar la carrera de Ballesteros en la anima- 
ción, cuenta con dos personajes femeninos protagónicos que ocupan los arquetipos narrativos de heroína y villana respectivamente.

\section{LOLA Y VIRGINIA: UNA LECTURA CON PERSPECTIVA DE GÉNERO}

Dirigida por Myriam Ballesteros y coescrita junto a Txema Ocio, la serie de animación Lola y Virginia (2006) se ha emitido en más de 95 países, entre ellos Turquía, Rusia, Estados Unidos, Brasil, Corea del Sur, Vietnam, India o África Subsahariana. En nuestro país, Disney Channel fue el primer canal en emitirla, en octubre de 2006, permaneciendo en antena hasta principios de 2009. Posteriormente, se emitió en La 2, cuya audiencia alcanzaba de media un $2,5 \%$ de porcentaje de share y, más tarde en Clan TVE, llegando a ser uno de las diez emisiones más vistas en TDT en 2010 con un 3,56\% (De la Torre Araus, 2011: 91). También lo emitieron otras cadenas como ETB, TV3, Nickelodeon España, Atresmedia, Flooxer y, en la actualidad, está disponible en Netflix. En 2006 obtuvo el premio Cartoon on the Bay a mejor serie de animación, y en 2012 la cadena italiana Rai2 la adaptó como una sitcom de acción real (26 episodios de 24 minutos) dirigida a un público adolescente ${ }^{8}$. La serie Lola y Virginia consta de 52 capítulos de 12 minutos de duración que cuentan la historia de las protagonistas que dan nombre a la serie. Lola tiene 12 años, vive en un barrio modesto y asiste a un instituto cuyos amigos resultan hilarantes. Un día, aparece Virginia, una niña rica y consentida a la que no le falta de nada para tener éxito y ser la más popular del instituto. Las tramas, basadas en los enredos y las peripecias de las protagonistas, dan lugar a situaciones cómicas.

Basándonos en al análisis de las fichas descritas en el apartado anterior, en las siguientes líneas completamos la información recabada. Así, podemos concluir que el aspecto físico de ambas avanza al espectador lo diferentes que son los personajes a nivel narrativo. Lola es bajita, regordeta, tiene los ojos verdes, la melena morena y lleva gafas. Vestida con un vestido rojo, calcetines y aspecto naíf, Lola contrasta con su rival Virginia, que es alta, tiene los ojos azules y una larga melena rubia. Viste con vaqueros, blusa con una " $V$ " que resalta su narcisismo, y zapatos de tacón rojo a juego con su bolso. Es así como, la audiencia más joven puede asumir que la sociedad relaciona a las mujeres poco interesadas por su físico como más inteligentes, arma que Lola utiliza para defenderse de los ataques de Virginia. Esta última, tan volcada en su imagen, no se interesa por la cultura ni el deporte. Los dos personajes protagonistas son redondos, es decir, tienen profundidad psicológica: piensan por sí mismas, mueven la acción (los guiones son character-driven) e introducen a los espectadores en su universo. Una historia que se articula en torno a la rivalidad entre el egocentrismo de Virginia y las ansias de justicia de Lola.

Si bien las dos protagonistas son heroína y villana respectivamente, y en cierto modo cumple con la narrativa tradicional en la que dos mujeres entran en conflicto, Lola y Virginia se aleja de estos planteamientos si profundizamos en las tramas de los episodios.

En ningún episodio aparece el arquetipo del "príncipe azul" que libera a la damisela en apuros. Ambas protagonistas son capaces de entrar en conflicto y salir de él sin rescate ni happy-ending. Los personajes además de tener agencia, son complejos: ni Lola es dócil y sumisa como los estudios Disney estaban acostumbrados a presentar originalmente a sus princesas de cuento, ni Virginia es una "bruja" que se transforma para engañarla. Las dos se alejan de ideales y son presentadas con sus defectos y virtudes. La serie ensalza la aceptación individual y busca conectar con el público, consiguiendo presentar un modelo de feminidad, tal vez más alternativo a lo que estamos acostumbrados a ver en la animación comercial.

Como toda villana en una acción narrativa, Virginia está dispuesta a hacer lo imposible con tal de fastidiar a la heroína Lola. Virginia se presenta como un personaje femenino dependiente porque tiene que usar su dinero, su belleza física y su malicia para conseguir sus objetivos. Lola, por su parte, logra sus objetivos dramáticos en cada capítulo utilizando su mejor arma: la inteligencia. Y, aunque Lola como heroína es capaz de salir airosa de situaciones complicadas, aparece un elemento clave en las historias con protagonistas femeninas: la sororidad. Lola no está sola en esta aventura, cuenta con la ayuda y apoyo de sus fieles amigas -tres niñas de su misma edad- de forma que la amistad entre mujeres hace avanzar la acción. Las amigas de Lola no sólo la escuchan y empatizan con ella, sino que se involucran en su objetivo dramático.

Por último, es importante señalar que las tramas de los capítulos progresan gracias a las 
emociones de las protagonistas, pero sin estar fundadas en el mito del "amor romántico".

Aunque el enamoramiento está presente en la serie como sentimiento que genera conflicto en la narración, no se aborda de una manera tradicional. Lola está enamorada de Carlos, un compañero del instituto que es utilizado como instrumento por Virginia para molestar. El amor, sentimiento que ha sido representado como eje de la feminidad, no se entiende en Lola y Virginia como un "amor romántico", aquel en el que la protagonista deja todo su universo tras ser liberada por el príncipe de sus sueños. Tampoco Carlos es retratado como un "príncipe azul", de hecho, se mantiene al margen de la rivalidad de las protagonistas porque solo le interesa jugar con sus amigos.

\section{CONCLUSIONES}

El género, como constructo cultural, puede influir en la manera que un/a creador/a audiovisual ve e interactúa con el mundo. Elegir el género del protagonista, villano o de cualquier personaje que participe en la acción condiciona la narración y la transforma en algo diferente. Es por ello que los contenidos dirigidos al público infantil pueden colaborar de una forma significativa en el logro de una sociedad más justa, donde niñas y niños tengan las mismas oportunidades para desarrollarse. En la actualidad, más allá de las variadas fórmulas de visionado o interacción que se pueden elegir, la ficción seriada continúa teniendo peso en el tiempo de ocio de la infancia y juventud. "Los, y sobre todo las jóvenes, extraen información de la ficción televisiva seriada y pueden convertirse en agentes de socialización (...) las series incorporan espacios de debate y comunicación, lo que constituye un nuevo foro para la educación entre iguales" (Menéndez, Figueras y Núñez, 2017, p. 390). Es fundamental que las productoras y los canales de televisión que elaboran contenidos para la infancia incorporen la perspectiva de género como mecanismo para cambiar las desigualdades entre niñas y niños. Si bien la construcción de los roles de género se realiza en función de la experiencia personal, de los modelos familiares y educativos, también lo hacen las representaciones que elaboran los medios de comunicación, en particular la televisión que ocupa un lugar privilegiado en la socialización, especialmente durante las primeras etapas de la vida. Como señala Isabel Menéndez, "Se deben incorporar-especialmente en el ámbito de la educación y especialmente con la población más joven - prácticas de alfabetización mediática con las que desactivar un sexismo que muchas personas ni siquiera perciben como tal" (2017, p. 24).

Reflexionar sobre los mecanismos del audiovisual resulta fundamental: preguntarse sobre la trama, los desenlaces, los valores ligados a los personajes femeninos, la construcción discursiva o el concepto de autoría... pero también leer el texto en clave más política, esto es, cómo se muestra el cuerpo de las mujeres, la noción de placer visual y la posibilidad de subvertir la mirada masculina. Como Myriam Ballesteros explica, "El hecho de que una mujer dirija, escriba un guion o produzca una película implica que hay una visión diferente porque, como mujer, te interesan otros temas y otras problemáticas" (2020). Para la creadora, esa mirada propia aporta diversidad. "Tu público, aunque intentes que guste tanto a chicos como chicas, siempre tiene una inclinación para lo que a ti te motiva más. A mí, por ejemplo, las series de violencia o las series de acción no me interesan nada" (Myriam Ballesteros, comunicación personal, 6 de marzo de 2020). Crear historias que rompan con los estereotipos de género y brindar una lección a las nuevas generaciones es aún una tarea ardua. El objetivo es que las niñas puedan sentirse representadas al insertar personajes femeninos que desempeñen todo tipo de arquetipos narrativos y representen personalidades muy distintas. Myriam Ballesteros subraya la importancia de trabajar en profundidad los personajes femeninos: "No me interesa coger un rol masculino y meter a una tía porque no me lo creo, no me llega, no me motiva. No es masculinizar a una mujer en un rol masculino" (2020). La creadora busca acabar con el ideal femenino de "compañera del héroe": "Mi visión es que las mujeres tengan roles protagonistas haciendo las cosas de otra manera -como en la realidad-, bien de forma más inteligente o más colaborativa, asociándose con otros... pero no ponerse un traje y salir espada en ristre" (Ballesteros, 2020). En este sentido, las historias de ficción de Ballesteros proponen representaciones novedosas en cuanto a construcción del género, algo preciso a la hora de crear nuevos relatos. Las representaciones subversivas pueden abordarse desde variables como la edad o el placer sexual; la amistad, solidaridad, el amor entre mujeres, el humor, el cuestionamiento de la maternidad/paternidad convencional o la discusión del amor romántico. "Es necesario interrogarse por la situación y posición de las mujeres respecto a los varones, la aparición o no del binomio domés- 
tico/público, la existencia de feminidad o masculinidad normativas, etc." (Menéndez, 2017, p. 24). En esta misma línea, Trinidad Núñez y Felicidad Loscertales advierten sobre la importancia de desarrollar el sentido crítico con los contenidos de animación dirigidos a la infancia con el objetivo de arrinconar estereotipos. "Tras escenarios encantados, números musicales coloristas o fascinantes personajes que atolondran con su bondad o su maldad, se esconden componentes ideológicos que deforman la realidad, potenciando una interacción social basada en el sexismo" (2008, p. 762). Para crear nuevos relatos con valores que fomenten la igualdad de género es, por tanto, indispensable que haya mujeres creadoras en activo.

Como hemos visto, en la animación, como sucede en el resto de la industria audiovisual, el porcentaje de mujeres en los puestos artísticos continúa siendo minoritario. La trayectoria de Myriam Ballesteros, nacida en los sesenta, ilustra los profundos cambios que han experimentado las mujeres en la sociedad española durante las últimas décadas. Sus años de formación coinciden con la llegada y consolidación de un régimen democrático cuyas nuevas legislaciones favorecieron el progreso social de las mujeres, no sólo en leyes que les podían afectar de manera más inmediata como el divorcio y el aborto, sino también en otros ámbitos que les permitieron alcanzar una presencia pública significativa.

Del mismo modo que la showrunner hizo hincapié durante la entrevista para esta investigación en lo importante que fue para ella su formación, nos resulta revelador enmarcar la figura de Ballesteros en un periodo y una generación que en el ámbito audiovisual tiene que ver con la puesta en marcha de un nuevo modelo universitario. Las antiguas escuelas oficiales -Escuela Oficial de Cinematografía y Escuela Oficial de Periodismo- en las que se formaron directoras de cine y televisión "pioneras" como Pilar Miró y Josefina Molina, suponían un acceso más limitado a la profesión. Es decir, su carácter de élite en el caso de la EOC hacía que la presencia femenina en sus aulas fuera testimonial.

Esta situación cambió radicalmente con la apertura de las nuevas facultades de Ciencias de la Información tanto en Barcelona (en el seno de la Universitat Autònoma de Barcelona en el curso 1971-1972) como en Madrid (en la Universidad Complutense un curso académico más tarde), que ofrecían estudios de Periodismo, Imagen y Sonido (que más tarde se convirtieron en los de Comunicación Audiovisual) y Publicidad y Relaciones Públicas. "En estos años, las aulas de las nuevas facultades se llenaron de miles de estudiantes, de los cuales un elevado porcentaje eran mujeres que primero pudieron acceder a becas o prácticas y más tarde lograron beneficiarse de su titulación a la hora de consolidar su puesto" (Cascajosa Virino y Martínez Pérez, 2015, p.12). Myriam Ballesteros forma parte de esa generación de mujeres españolas que accedió a una formación universitaria consolidada en imagen y sonido. La reordenación y ampliación de la universidad pública se materializó en una estructura que promovió la incorporación de las mujeres a los medios de comunicación, forjándose verdaderamente como mecanismo de igualdad. Del mismo modo, la expansión del mercado televisivo -marcado por la creación de las televisiones autonómicas y privadas- ofreció a esas promociones la oportunidad de progresar laboralmente. Por sus más de treinta años de experiencia en medios, nuestro acercamiento a la trayectoria de Myriam Ballesteros ilustra cómo una auténtica transformación social que contemple los derechos y oportunidades de las mujeres pasa por su incorporación a todos los ámbitos del audiovisual, incluida la animación. Pero también sirve como reconocimiento a una generación de mujeres que se abrieron camino en un mundo profesional hostil. 


\section{NOTAS}

1 Véase: http://www.rtve.es/corporacion/rc/ods5/ (Acceso: 20/03/2020).

2 John Lasseter ha sido director creativo de los estudios Pixar Animation Studios, Walt Disney Animation Studios y DisneyToon Animation Studios hasta finales del 2018 y ha ejercido también, como Asesor Creativo en Walt Disney Imagineering. Ha ganado dos Oscars, uno por el corto de animación Tin Toy, en 1989, y otro por el largometraje Toy Story, en 1996: https://elpais.com/cultura/2018/06/09/actualidad/15285 60309_519472.html (Acceso: 02/03/2020).

3 Tim Burton comenzó a trabajar como animador en Disney en la década de los ochenta.

4 La filmografía de Myriam Ballesteros está disponible en su página web: http://mbproducciones.com/myriamballesteros/ (Acceso: 18/03/2020).

5 Véase: “Mondo TV Iberoamérica y Myriam Ballesteros firman un acuerdo para dos series de animación", recuperado de: https://www.audiovisual451.com/mondo-tviberoamerica-y-myriam-ballesteros-firman-un-acuerdo-parados-series-de-animacion/ (Acceso: 25/06/2020).

6 Véase https://animacionesmia.com/sobre-mia/ (Acceso: 20/03/2020).

7 La ficha parte de la metodología propuesta por Cuenca Orellana en su tesis doctoral La construcción del género en las películas de animación de Pixar Animation Studios entre 1995 y 2015. Modelos de masculinidad, feminidad y relaciones entre personajes (2019). Las categorías de análisis están inspiradas en el Test Bechdel (1985) así como en los textos: Estrategias de guion cinematográfico (SánchezEscalonilla, 2014), El viaje del escritor (Vogler, 2002) y en El guion (Mackee, 2011).

8 La adaptación a acción real supuso un hito en la animación española. Como explicaba Sergi Reitg, consejero delegado de Imira, "En España es la primera vez que una tira de dibujos animados pasa a imagen real" (Gallo, 2011).

\section{REFERENCIAS BIBLIOGRÁFICAS}

- Ballesteros, M. (2020). Entrevista con Myriam Ballesteros [comunicación personal, 6 de marzo de 2020].

- Bengoechea, M., Díaz-Aguado, M.J., Falcón, L., López Díez, P. y Pérez, Á. (2005). Infancia, Televisión y Género: argumento para la elaboración de una guía de contenidos no sexistas para la programación infantil de televisión. Madrid. Instituto Oficial de Radio y Televisión RTVE.

- Cascajosa Virino, C. y Martínez Pérez, N. (2015). Mujeres en el aire: haciendo televisión. Cuadernos Tecmerin.

- Cuenca Orellana, N. (2019). La construcción del género en las películas de Pixar Animation Studios entre 1995 y 2015: modelos de masculinidad, feminidad y relaciones entre personajes [Tesis doctoral, Universidad de Burgos].

- De la Torre Araus, Á. (2011). ¿Qué ven los niños? En Fernández Martínez, P. (comp.). Los niños y el negocio de la televisión: Programación, consumo y lenguaje (pp. 90-104). Comunicación Social.

- Domínguez Morante, L. (2015). Pixar's New fairy tale Brave: a feminist redefinition of the hero monomyth. Revista de Estudios Norteamericanos, (19), 49-66. Recuperado de:

https://revistascientificas.us.es/index.php/ESTUDI OS_NORTEAMERICANOS/article/view/4615

- Estévez, A. (2015). El héroe en el cine de animación contemporáneo de principios del siglo XXI [Tesis Doctoral, Universidad Complutense de Madrid].

- Finch, C. (2011). El arte de Walt Disney: De Mickey Mouse a Toy Story. Barcelona: Lunwerg.

- Gallo, I. (2011, 31 de octubre). De dibujo animado a imagen real. El País. Recuperado de: https://elpais.com/diario/2011/10/31/radiotv/1 320015605_850215.html

- González Hijano, L. (2004). Mujeres en la industria de la animación española. HUM 736: Papeles de cultura contemporánea, (5), 41-45. Recuperado de: https://dialnet.unirioja.es/servlet/articulo?codigo $=3321022$

- Jiménez Sánchez, Á.; Lavín, JM y Gómez Isla, J. (2019). Érase una vez..., la animación infantil española. RISTI. Revista Ibérica de Sistemas e Tecnologias de Informacao (no E20, 05/2019), 3648. Recuperado de:

http://www.risti.xyz/issues/ristie20.pdf

- López Monjas, C. (2016). Mujeres con mucho 'ánimo'. Academia: Revista del Cine Español, (219), 16-18. Recuperado de: https://dialnet.unirioja.es/servlet/articulo?codigo $=6330477$

- Martínez, González E. (2011). Los mundos [teóricos] de Coraline: Psicoanálisis, Postfeminismo y Postmodernismo en el cine de animación. Con $A$ de animación, (1), 76-96. DOI:

https://doi.org/10.4995/caa.2011.862

- Mackee, R. (2011). El guion. Story: Sustancia, estructura, estilo y principios de la escritura de guiones. Alba Minus.

- Menéndez Menéndez, I. (2017): Entre el neomachismo y el retrosexismo antifeminismo contemporáneo en las industrias culturales. Prisma Social: revista de investigación social, (especial 2), 1-30. Recuperado de: https://revistaprismasocial.es/article/view/1544

- Menéndez Menéndez, I.; Figueras Maz, M.; Núñez Angulo, B. (2017): Consumo y percepción juvenil sobre la ficción seriada televisiva: influencia por sexo y edad. OBETS: Revista de Ciencias Sociales, 12(2), 369-394. Recuperado de: 
https://revistaobets.ua.es/article/view/2017-v12n2-consumo-y-percepcion-juvenil-sobre-la-ficcionseriada-televisiva-influencia-por-sexo-y-edad

- Núñez Domínguez, T. y Loscertales Abril, F. y (2008). El cine de animación visto en casa: dibujos animados y TV. Comunicar: Revista científica iberoamericana de comunicación y educación, (31), 757-763. Recuperado de:

https://dialnet.unirioja.es/descarga/articulo/4277 341.pdf

- Paik, K. (2007). To Infinity and Beyond. The Story of Pixar Animation Studios. Chronicle Books.

- Propp, V. (1998). Morfología del cuento. Akal.

- Sánchez-Escalonilla, A. (2014) Estrategias de guion cinematográfico. Ariel.

- Vogler, C. (2002). El viaje del escritor. Las estructuras míticas para escritores, guionistas, dramaturgos y novelistas. Ma Non Troppo.

- Yébenes Cortés, P. (2016). ¡Felices 100! Academia: Revista del Cine Español, (219), 8-11.
ANEXO

Ejemplo de ficha de análisis. Ficha 1

\begin{tabular}{|c|c|}
\hline Título del episodio & El truco de la cebolla $(1 \times 1)$ \\
\hline Personaje & Lola \\
\hline Género del personaje & Femenino \\
\hline \multirow[t]{2}{*}{ Representación externa } & $\begin{array}{l}\text { Ropa: viste un vestido rojo, } \\
\text { calcetines y zapatillas. } \\
\text { Aspecto naif. }\end{array}$ \\
\hline & $\begin{array}{l}\text { Físico: tiene ojos verdes, es } \\
\text { pequeñita, regordeta, pelo } \\
\text { moreno, media melena, piel } \\
\text { blanca y gafas. }\end{array}$ \\
\hline \multirow[t]{4}{*}{ Objetivo dramático } & $\begin{array}{lrr}\text { Persigue su objetivo } & \text { sú } \\
\text { dramático: Lola está } \\
\text { enamorada de Carlos desde }\end{array}$ \\
\hline & $\begin{array}{l}\text { la guardería y se ha } \\
\text { propuesto besarle. Para }\end{array}$ \\
\hline & $\begin{array}{l}\text { ello, quiere ser la } \\
\text { protagonista en la función } \\
\text { del colegio y que así, Carlos, }\end{array}$ \\
\hline & $\begin{array}{l}\text { que es el protagonista } \\
\text { masculino la bese. }\end{array}$ \\
\hline $\begin{array}{l}\text { Acciones que realiza para } \\
\text { alcanzar su objetivo } \\
\text { dramático }\end{array}$ & $\begin{array}{l}\text { Relacionadas con los } \\
\text { sentimientos y emociones: } \\
\text { rivalidad, envidia, } \\
\text { enamoramiento. }\end{array}$ \\
\hline $\begin{array}{l}\text { Obstáculos que encuentra } \\
\text { para alcanzar el objetivo }\end{array}$ & $\begin{array}{l}\text { Virginia quiere que Carlos } \\
\text { se fije en ella y que así Lola } \\
\text { no pueda tener ninguna } \\
\text { oportunidad con él. }\end{array}$ \\
\hline $\begin{array}{l}\text { Alcanza el objetivo de la } \\
\text { narración }\end{array}$ & $\begin{array}{l}\text { Necesita ayuda para } \\
\text { lograrlo: Lola pide consejo a } \\
\text { sus amigas para pasar la } \\
\text { prueba y ser seleccionada } \\
\text { como protagonista, y le } \\
\text { recomiendan que lleve una } \\
\text { cebolla. Virginia se la roba y } \\
\text { la utiliza, pero Carlos es } \\
\text { alérgico. Lola tiene le hace } \\
\text { el boca a boca, ganando así } \\
\text { la apuesta. }\end{array}$ \\
\hline $\begin{array}{l}\text { Arquetipo narrativo y su } \\
\text { función }\end{array}$ & Heroína. Servir y proteger. \\
\hline
\end{tabular}

